\title{
The assessment of the environmental impact of the construction project
}

\author{
Natalia Kataeva $^{1,{ }^{*}, \text { Ekaterina } \text { Berezina }^{1} \text {, Alexey Sysolyatin }{ }^{1} \text { and Anzhelika Borisova }}{ }^{2}$ \\ ${ }^{1}$ Vyatka State University, Moskovskaya street, 36, Kirov city, Kirov region, 610000, Russia \\ ${ }^{2}$ Moscow State University of Civil Engineering, 129337, 26, Yaroslavskoe Shosse, Moscow, Russia
}

\begin{abstract}
The article is devoted to the research of the main trends and problems concerning the development of measures for the protection and rational use of the environment in Russia as well as the assessment of the environmental impact. The main sources of the regulating and legal information were analysed. As the result of the research, of the analysis and synthesis of these documents, the authors offered the basic methodology for the assessment of the environmental impact of the construction projects. The authors developed some recommendations about contents of the sections of the assessment of the impact of the construction project on the environment. The recommendations presented in the article are useful to all the participants of the investment-and-construction process, for the contractors involved in development of the project documentation, for the employees who carry out the state assessment of the environmental impact of the projects.
\end{abstract}

\section{Introduction}

In recent decades, the entire civilized world has paid more attention to the issues of effective environmental management and control [1], where the paramount importance is given to the compliance with environmental regulations and standards at all stages of implementing any project [2]. Even at the stage of preparing project documentation, it is important to assess the environmental impact of the planned activity in future and reduce it to a minimum. This is fully consistent with the basic principles of environmental management, such as the principle of anticipation and precaution of solving environmental problems, the principle of timeliness and the principle of functional integration.

To implement this idea, Russia adopted Federal Law No. 174-FZ of 23 November 1995, "On Ecological Expertise". Thanks to the adoption of this Federal Law, an effective mechanism has been created for taking into account the environmental component when making economic decisions and the scope of supervisory and regulatory authorities has been increased [3]. Environmental impact assesment is defined in the text of the law as "setting compliance of documents and (or) documentation substantiating the economic and other activities planned in connection with the environmental expertise object to the environmental requirements established by technical regulations and legislation in the field of environmental protection, in order to prevent negative impacts of such activities on the environment. " The

* Corresponding author: doptaganka@yandex.ru 
above law fully correlates with international environmental law and is crucial for implementing the environmental doctrine of the Russian Federation [4]

However, as experts note, the environmental impact assessment has lost its advantage recently and needs improving [5]. The state of the system as a whole can be assessed as critical. The reasons for this situation are aggravated paperwork, increasing deformation of the law, abuse in conducting research and reducing the quality of expert work.

The Order of the Russian Federation State Committee on Environmental Protection dated May 16, 2000 No. 372 “On Approval of Regulation on Environmental Impact Assessment of the Planned Economic and Other Activities in the Russian Federation" was called up to rectify this situation. According to the Regulation, environmental impact assessment of a planned economic or other activity (EIA) is a process that facilitates the adoption of environmentally oriented management decisions on implementing planned economic and other activities by identifying possible adverse impacts, assessing environmental impacts, taking into account public opinion, developing measures to reduce and prevent impacts [6].

It is important to note that the EIA is of a precautionary nature and is aimed at efficient environmental management and environmental protection. These facts increase the effectiveness of the environmental impact assessment system as a whole, since it is easier to prevent a negative impact on the environment than to eliminate the consequences of this impact.

Despite the variety of laws and regulations, regulatory documents used in the development of EIA for the project [7], experts do not cease to talk about common and frequent errors in pre-project and project documentation provided for the state environmental impact assessment [8]. Such omissions prevent prompt and effective going through the commission and receiving a positive conclusion. Customers and developers of the documentation are forced to spend additional funds to finalize the documentation and re-pass the examination in the relevant bodies of authority.

\section{Materials amd methods}

Theoretical and methodological basis was conceptual studies of the main provisions of environmental management and environmental impact assessment, the interrelationships between its elements (subsystems) using an innovative approach to create a regional economy that is competitive and socially responsible from the environmental point of view, as well as research problems in the field of environmental impact assessment of projects at the regional level, as well as environmental management problems based on analytical and expert methods, proposed in domestic and foreign literature

The substantiation of the main provisions of the work concerning the proposed methodology for conducting environmental impact assessment of projects was carried out using traditional methods of deduction and induction, structural and functional analysis, abstract logical judgments and assessments, systematic and integrated approaches, and the subsequent prognostic synthesis of the information obtained. The empirical part of the work is based on the use of monographic methods of information analysis.

\section{Results}

The study examined the main trends and problems in the development of environmental management and environmental impact assessment in Russia, methods used to conduct environmental impact assessment of projects, and proposed a basic methodology for environmental impact assessment of projects. 
In order to assist the developers in preparing project documentation provided for the state environmental impact assessment, it was decided to investigate regulatory documents related to this issue and formulate recommendations.

The main sources of regulatory and legal information used were:

- Resolution of the RF Government of February 16, 2008 No. 87 "On the composition of sections of project documentation and requirements for their content";

- Order of the RF State Committee on Ecology No. 372 of May 16, 2000 "On Approval of the Regulation on Environmental Impact Assessment of the Planned Economic and Other Activities in the Russian Federation";

- SNiP 11-02-96 "Engineering surveys for construction. The main provisions ";

- SP 11-102-97 "Engineering and environmental surveys for construction".

The result of the study, analysis and synthesis of these documents were methodological recommendations. They contain specially arranged information, establish the order and specify important points in conducting environmental impact assessment.

Recommendations are useful for participants and performers involved in the development of project documentation provided for state environmental impact assessment. The goal is to summarize and make more specific the materials on the content of the section "Environmental Protection Measures" in order to simplify the work of design organizations and reduce the number of errors. There is no doubt that the improvement of the methodological apparatus within the framework of environmental impact assessment will contribute to improving the quality of public services rendered and improving the environmental situation in the regions.

Methodological recommendations contain a list of sections with a brief description of the minimum, which should be included in the technical report on the engineering and environmental surveys carried out in the framework of EIA. The content is presented in the form of a flowchart (Figure 1).

Any environment description and assessment, impact on it is carried out on the basis of engineering surveys. In particular, environmental engineering, which is an independent type of survey and is carried out by design and other organizations that are certified to carry out such work. Separate types of work should be done by special organizations or qualified experts in the relevant areas in compliance with all the requirements set by regulatory documents and state standards.

As the expert experience shows, the preparation of a project for environmental impact assessment goes through three stages. The first stage involves compiling technical specifications, collecting and interpreting baseline data.

The second stage includes creating the project with indicating the sources of environmental pollution adjacent to the construction site, the assessment of identified and possible impacts. It also discusses options for reducing or eliminating adverse environmental impacts.

The final, third stage involves the analysis of project documentation and passing state environmental impact assessment in the relevant bodies of authority.

The project development should imply:

- analysis of the impact on surface and groundwater;

- analysis of the impact on soil and plant composition;

- analysis of possible air pollution;

- acoustic impact analysis;

- analysis of the use of adjacent territories and restoring influence;

- development of environmental protection measures.

The above list indicates the need for a whole range of environmental studies to detect impacts on key environmental components. Therefore, it is important to determine the optimal list of definitions reflecting regional specificity, planned works and other factors. For 
example, it is impractical to carry out an environmental acoustic impact assessment in the construction of a linear object.

In the process of preparing the documentation, it is important to determine the completeness of exploration of the construction area, the level of violation of environmental objects, the options for adverse effects. Detailing these points will allow to separate the areas for which it is necessary to carry out a detailed study, and those for which it is only necessary to confirm the invariance of the state.

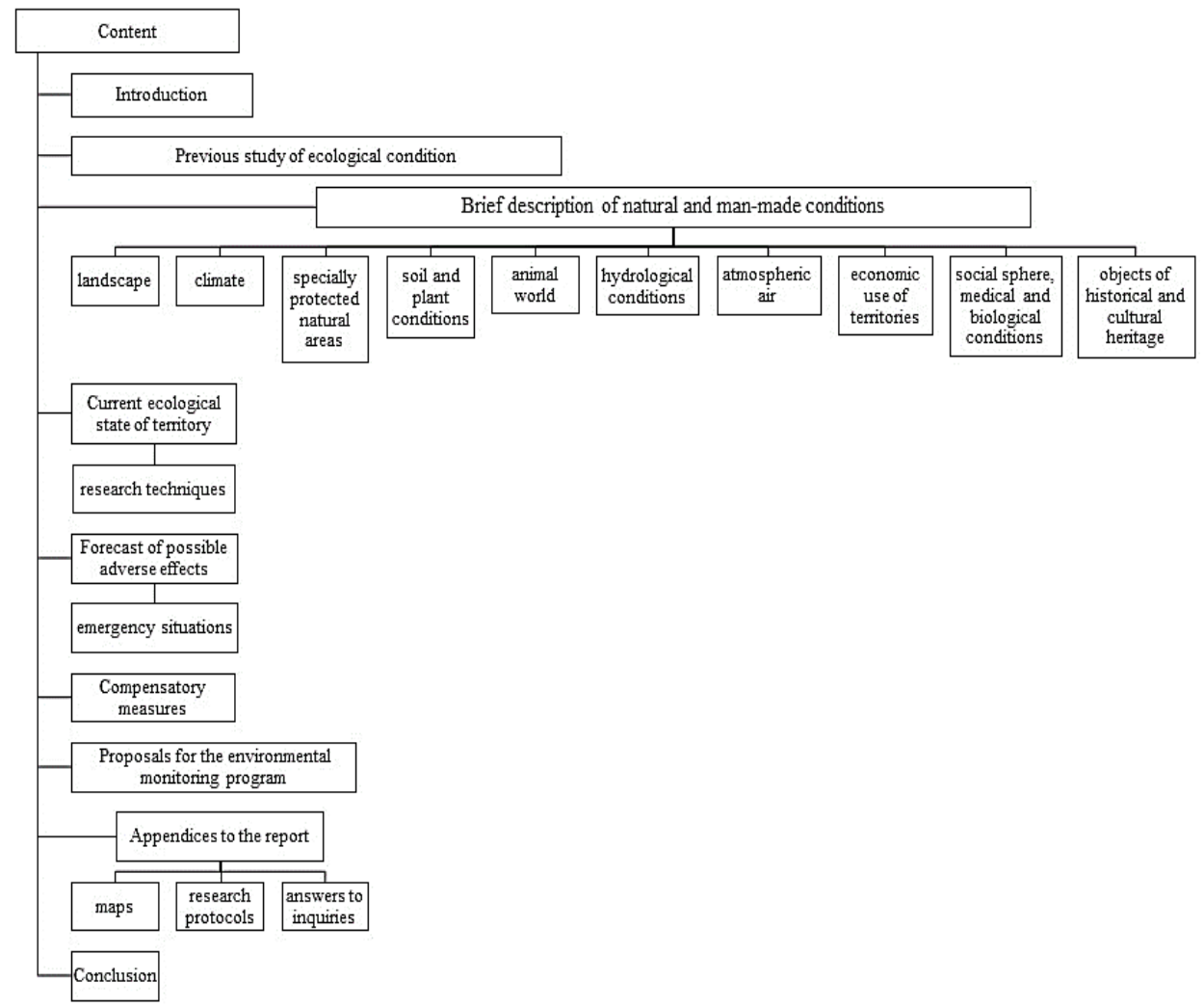

Fig. 1. Structural content of environmental impact assessment [9].

Based on the results of the survey, the report is compiled that contains sufficient and necessary information for assessing the environmental impact of the planned linear facility. The content of the technical report is regulated by paragraphs $16-29$ of Section Eight of the SNiP 11-02-96 [10]. The scale of the exploration can be determined on the basis of SP 11 102-97 [11]. After studying these documents specifically for linear objects we got the following list of sections included in the report on engineering and environmental survey.

Introduction contains brief data on the justification of the survey, formulates their tasks, information about the features of the designed linear object. It also provides information on the types, volumes and methods of survey, describes work performers, work timing.

The first section "Previous study of environmental conditions" determines the availability of materials from surveys of previous years conducted on the selected territory, published and requested data from specially authorized bodies in the field of environmental protection. It is possible to provide information on similar linear objects operating in a similar landscapeclimatic environment.

The second section "Brief description of natural and man-made conditions" covers the description of the relief and climate of the region, the landscape features of the area, the 
degree of its development. Thus, the Kirov region territory is characterized by the presence of wetlands on the territory of the object, salt licks and other features. It is important to note the presence of specially protected natural areas, indicate their status, value, purpose.

The activities planned during the project development may concern three categories:

- physical environment - atmosphere, water, soil, physical processes;

- biological environment - animal and plant world, specially protected areas;

- socio-economic environment - cultural monuments, employment, infrastructure, environmental management, medical and biological conditions, etc.

According to the indentified categories it is logical to include some subsections in the second section of the report.

The subsection "Soil and plant conditions" may contain information on the types of soils and physico-chemical characteristics of the composition. It is also necessary to include materials on vegetation cover - species diversity, plant communities, to note the presence of rare, relict species on the territory of the object. The number of the plant world representatives, their status and the system of protection or renewal should be indicated as specifying data.

The subsection "Animal world" displays data on the species composition, distribution by habitat, and migration routes. It is important to indicate specially protected, valuable species, if any, and to suggest a system for their protection.

We consider it necessary to include a separate subsection containing information on hydrological conditions. Here it is necessary to give the description of surface waters, to note existing springs, wells and to investigate underground waters, to give a brief conclusion about the chemical composition, the possibilities of using sources for drinking or technical purposes. This information is relevant in the development of EIA documentation, as the Kirov region has significant water resources, which are based on surface and groundwater. In total, there are 19753 rivers with 66.6 thousand kilometers of length, 4500 lakes, 3 large and about 700 small reservoirs in the region. These figures indicate the need for accounting and control of water resources. In addition, engineering and environmental surveys in this direction will contribute to an increase in the degree of water resources exploration, which is $4.24 \%$ at the moment [12].

The subsection "Economic use of the territory" contains information on the structure of the land fund, infrastructure, environmental management, and sources of pollution. If the territory is not involved in the production or non-production sphere, or there is no economic activity on it, then this subsection can be excluded.

Another specific subsection "Social sphere" is relevant only when a linear object is situated near settlements. This part of the report displays data on the population (number, employment, demographic characteristics), biomedical conditions and morbidity.

After the Federal Law "On the objects of cultural heritage of the peoples of the Russian Federation" came into force, the subsection "Objects of historical and cultural heritage" has recently become relevant and is included in the report only if there are historical and cultural monuments on the territory of the gas pipeline, which is unlikely.

The third section - "The current ecological state of the territory" - contains data on the analysis of the ecological state of the area, including a description of the components of natural environment, terrestrial and aquatic ecosystems. It provides information on the resistance of the latter to anthropogenic influences and methods of recovery. It is advisable to provide data on chemical pollution of water bodies and soils, emissions of harmful substances into the atmosphere, mechanical pollution of the territory, biological pollution (spread of diseases, pathogens, animal relocation), geological pollution (provoking landslides, waterlogging and the like).

This section can include a subsection "Research techniques" and reveal the order of research, describe laboratory tests, the course of their conduct, the techniques used, give 
references to state standards and environmental regulatory documents. Ecological studies of atmospheric air, soil, surface and groundwater to analyze their contamination on the construction site of a linear facility should contain a set of monitored indicators, in accordance with current industrial construction standards.

The next fourth section is "Forecast of possible adverse effects". It specifies the parameters of expected environmental pollution, indicates the terrain, the area of the influence halo of the linear object. The analysis of the environmental risk is carried out for individual components: pollution of the soil, air, water bodies. Careful attention should be paid to the forecast of deterioration of flora and fauna, socio-economic sphere.

A separate subsection can be given to assessment of the potential impact of an unplanned event, for example, damage to gas pipelines, emergency situations, emissions of pollutants, fuel spills. Information should be provided on the limits of the possible spread of negative impacts and their consequences.

Based on the fact that the purpose of environmental impact assessment is to find ways to reduce or eliminate negative impacts of the object, one of the most significant sections of the report is the fifth section "Compensatory Measures". It contains tips and suggestions for preventing or minimizing the adverse effects of the project, as well as recommendations for restoring the affected environment.

"Proposals for the environmental monitoring program" - the sixth section -continues the previous one. It is necessary to determine the stages of work where monitoring will be carried out, its goals and objectives for each stage separately. It provides a list of components of the natural environment that are planned to be monitored. For linear objects, it is advisable to monitor the state of atmospheric air, surface water and wells, if they exist on the territory of the zone of the object influence, soil cover, animal and plant world. It should be noted that the list of monitored parameters may differ at different stages of the work. This is primarily due to the lack of a source of pollution at some point of economic activity. A list of sites for monitoring is provided - it is important to cover the areas that are most susceptible and sensitive to predicted negative impact. The report developer has a right to indicate a list of specific pollutants that are mandatory for research and that are the most significant. It is necessary to forsee in the section the possibility of changing monitoring sites, introducing additional definitions, adjusting the frequency of environmental monitoring.

The seventh section "Appendices to the technical report" - contains copies of the following documents:

- document on permission to conduct engineering and environmental surveys;

- technical desigh specification and survey program;

- protocols for the study of samples of soil, water, and atmospheric air;

- certificates of accreditation of laboratories participating in the conduct of chemical and analytical tests;

- documents received from the authorities in the course of the survey;

- summary tables of the research, analysis and structure of impacts;

- various statistics.

The seventh section should contain graphic data. These include environmental maps with the display of areas affected by negative factors. Maps can reflect the current and predicted state of the terrain, areas of pollution distribution and location of their sources, places of the highest pollution concentration. The scale of the maps included in the section depends on the purpose of engineering and environmental surveys and when justifying investment in construction is from 1: 50,000 to $1: 10,000$, in surveys for a construction project - from 1: 5,000 to $1: 2,000$.

In conclusion, the report formulates conclusions on the basis of the conducted research on economic activity feasibility. The conclusion is made about the significance of various 
types of negative environmental impact while implementing planned and unplanned activities.

As a mandatory subsection it is recommended to include an assessment of hydrological conditions on the territory of proposed economic and other activities. The section containing proposals for preventing and minimizing adverse effects of emergency situations at the facility is called "Compensatory Measures" in this manual.

\section{Conclusions}

2017 was proclaimed the Year of Ecology in the Russian Federation. The Government of the Russian Federation, in the instruction of 2 June 2016, approved the plan of major events aimed at improving the situation described above. In particular, Section II of the plan "Standardization of the impact on the environment and the transition to the best available technologies", the first item is "improving legislation in terms of environmental impact assessment, ecological expertise and introducing strategic environmental assessment". There is every reason to believe that these actions will be the beginning of improving the mechanism and strengthening the role of environmental impact assessment of projects, technologies and government programs.

The developed recommendations are not only a theoretical generalization of regulatory documents, but also suggest practical application, given the urgency of improving the methodological basis for developing pre-project and project documentation for submitting to the state environmental impact assessment for large and small enterprises. It is possible to create information handouts in the form of booklets, brochures, leaflets.

Working out such "manuals" will undoubtedly contribute to improving the quality of public services rendered and improving the environmental situation in the country, increasing the level of environmental awareness.

\section{References}

1. A. Sozinova, E. Zhelnina, International Journal of Economics and Financial Issues 6(S1), 52-56 (2016)

2. A. Grabar, A. Nechaev, Collection of materials: "Vyatka State University" 1, 2075-2078 (2015)

3. G. Dyakova, S. Izmaylova, A. Mottaeva, E. Karanina, IOP Conf. Series: Earth and Environmental Science 90, 012218 (2017) doi :10.1088/1755-1315/90/1/012218

4. I. Markina, A. Sharkova, Journal of Applied Economic Sciences 9(4), 687-693 (2014)

5. A. Mottaeva, E. Vasilyeva, MATEC Web of Conferences 239, 04019 (2018)

6. G.N. Semenova, Role of accounting and taxation in the financial development of business 1, 23-26 (2017)

7. A. Sozinova, In the world of scientific discoveries 11-10 (47), 162-170 (2013)

8. O. Crassov, Environmental law, Textbook (Norma - INFA-M, Moscow, 2012)

9. K. Kunanbayeva, A.Gorovoy, A. Butyrin, MATEC Web of Conferences 193, 05048 (2018)

10. A. Mottaeva, MATEC Web of Conferences 193, 01022 (2018) doi.org/10.1051/matecconf/201819301022

11. I. Potekhin, V. Mischenko, A. Mottaeva, A. Zheltenkov, E3S Web of Conferences 33, 03020 (2018) doi: 10.1051/e3sconf/20183303020 